Help-seeking behaviour for internalizing problems:

Perceptions of adolescent girls from different ethnic backgrounds

Running head: Ethnic background \& help-seeking behaviour

CETH-2010-0149

Revision $16^{\text {th }}$ January 2013

Ilse J.E. Flink, $\mathrm{Msc}^{1 \S}$, Tinneke M.J. Beirens, $\mathrm{PhD}^{1}$, Dick Butte, $\mathrm{MA}^{2}$, \& Hein Raat, M.D., $\mathrm{PhD}^{1}$

${ }^{1}$ Department of Public Health, Erasmus MC - University Medical Centre Rotterdam, Dr Molewaterplein 50, PO box 2040, 3000 CA Rotterdam, the Netherlands

${ }^{2}$ Department of Youth Monitoring, GGD Rotterdam Rijnmond -Municipal Health Service Rotterdam Rijnmond, Schiedamsedijk 95, 3011 EN Rotterdam, the Netherlands

${ }^{\S}$ Corresponding author

Contact details corresponding author:

Email address: i.flink@erasmusmc.nl

Telephone number: +31 107038498

Fax number: +31107089370 


\section{Help-seeking behaviour for internalizing problems: Perceptions of adolescent girls from different ethnic backgrounds}

Objective: Although adolescent girls from ethnic minorities are at an increased risk of internalizing problems (e.g. depression), only a small fraction seeks formal help for these problems. To enhance help-seeking for internalizing problems among ethnic minority adolescent girls, insight into their help-seeking behaviour is required. This study explored the perceptions of adolescent girls from different ethnic backgrounds regarding their help-seeking behaviour for internalizing problems.

Design: A qualitative study using Focus Group Discussions (FGDs) was employed. Eight FGDs were conducted with 50 adolescent girls of mostly Turkish $(n=23)$, Moroccan $(n=13)$, and Dutch $(n=10)$ backgrounds recruited from Rotterdam, a multicultural city in the Netherlands. FGDs were conceptually framed within a help-seeking model, facilitated by a vignette and analysed using NVivo software.

Results: When describing the internalizing problems presented in the vignette, participants of non-Dutch FGDs tended to state the causes of the problems (e.g. lack of attention) whereas participants of Dutch FGDs mentioned the emotional state. Participants did not perceive the presented internalizing problems as severe. If participants were to face internalizing problems of their own, their decision to seek help would be hampered by negative attitudes towards professionals and school-based services. Particularly in non-Dutch FGDs the fear of parental and friend's reactions was identified as a barrier. Participants identified their mother and a good friend as primary sources of help.

Conclusion: In this study, adolescent girls of Turkish, Moroccan and Dutch backgrounds had difficulty recognizing the severity of internalizing problems, and various barriers could hamper their decision to seek help. To enhance utilization of mental health services by youth, promoting 
a change in their attitudes towards mental health/school-based services is recommended.

Guaranteeing confidentiality within school-based services, and training for professionals in communicating with adolescent girls, may also prove beneficial. In ethnic minorities, tackling the negative reactions of family/friends requires attention.

Keywords: Adolescents, mental health, help-seeking behaviour, culture, minority health, qualitative research 


\section{Introduction}

Internalizing problems, defined as problems that are mainly within the self (Achenbach and Rescorla, 2000), like depression and anxiety, have a great impact on adolescents. Declining school performance, school absenteeism, loss of social relations and substance abuse are some of the frequently reported outcomes of internalizing problems (Carlson, 2000, Simon, 2009). On the long run, internalizing problems can lead to co-morbidity and suicide (Harrington et al., 1990, Shaffer et al., 1996). Studies have shown that adolescent females are at an increased risk of developing internalizing problems compared to male counterparts (Jorm, 1987, Kuehner, 2003). The ethnic minority status has been found to place them at an even higher risk of internalizing problems (Stevens et al., 2005, van Oort et al., 2006, McLaughlin et al., 2007). Therefore, early detection and treatment of these problems in this group is of utter importance.

Most ethnic minority adolescents do not seek formal help for mental health problems and rates of mental health service utilization are low compared to the majority group (Garland et al., 2005). For example, a study in the United States found that African American and Asian American/Pacific Islander youth were half as likely to receive any type of mental health care compared to their White American counterparts, even after controlling for risk factors associated with mental health care use (Garland et al., 2005). The differences were particularly large for outpatient care though differences were also found for informal care like self-help groups. A recent Dutch study revealed that Moroccan girls were less likely (RR 0.73) to use youth mental health care services than Dutch girls (de Haan et al., 2012). Shame, stigma, fear of gossip and interethnic differences in help-seeking patterns such as solving problems within the ethnic and religious community have been suggested to contribute to the lower rates of mental health service utilization among ethnic minorities (Lawrence et al., 2006, Goldston et al., 2008). For ethnic minorities residing in the Netherlands, such as the 
Moroccans and the Turks, it has further been suggested that "a strong commitment to Islamic religious practices" (Knipscheer and Kleber, 2005) and a collectivistic background, which "includes a sense of interdependence and of one's status as a participant in a larger social unit" (Sampson, 1988), as opposed to an individualistic background, which places emphasis on independence and is more common in the Dutch majority, may also contribute differences in utilization of mental health services (Knipscheer and Kleber, 2005).

To enhance help-seeking for internalizing problems in adolescents from ethnic minorities, it is important to explore their help-seeking behaviour for these problems. As proposed by Cauce et al. (Cauce et al., 2002) help-seeking behaviour should be considered a protracted process which begins with the time when a problems is first noticed. A focus on the process of help-seeking rather than help-getting will more fully account for the influence of culture and context (Cauce et al., 2002). To date, a few studies have investigated the mental health help-seeking pathway of adolescents from different ethnic backgrounds (Molock et al., 2007, Lee et al., 2009) however; none of these studies have focused specifically on perceptions of adolescent girls regarding their help-seeking behaviour for internalizing problems. Since adolescent females from ethnic minorities are considered a high risk group with regard to internalizing problems (Stevens et al., 2005, van Oort et al., 2006, McLaughlin et al., 2007) it is of interest to focus on the help-seeking behaviour of this specific group.

Hence, the aim of this study was to explore the perceptions of adolescent girls from different ethnic backgrounds regarding their help-seeking behaviour for internalizing problems.

\section{Theoretical framework}

A three-stage model for mental health help-seeking in adolescents, developed by Cauce et al. 
(Cauce et al., 2002), was used as a theoretical framework for exploring the influence of ethnic background on adolescent girl's perceptions of help-seeking behaviour for internalizing problems (Figure 1). Stage I in the pathway, referred to as problem recognition, takes epidemiologically defined need and perceived need into account. Stage II, the decision to seek help, consists of a coercive and voluntary process of which the latter is largely determined by attitudes and beliefs. Stage III, service selection, looks at whom adolescents and their families turn to when dealing with a mental health problem. Context and culture are hypothesized to influence all three stages of help seeking. It is important to note that the stages defined in this model are interrelated but not necessarily sequential, indicated by the double-headed arrows pointing forward and backward. A problem may be desefined differently once help has been sought. Additionally, it is not unusual for an individual to pass back to a stage more than once to consult different sources of information or help (Cauce et al., 2002).

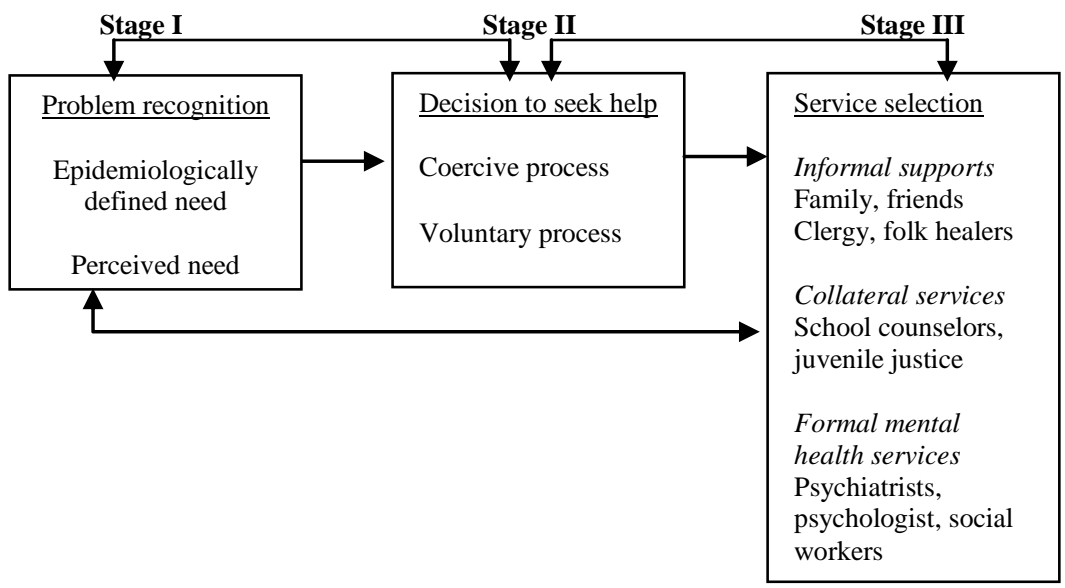

Figure 1. A three-stage model for mental health help-seeking among adolescents

In order to add depth to the three-stage model for mental health help-seeking among adolescents (Cauce et al., 2002), concepts from the latest version of the health belief model by Rosenstock et al. (Rosenstock et al., 1988) were also taken into account. These concepts related to perceived severity (how severe are internalizing problems), and perceived barriers and facilitating factors (what hampers or facilitates help seeking). 


\section{Methods}

\section{Design and Participants}

A qualitative study using Focus Group Discussions (FGDs) was employed. FGDs are an effective qualitative method that uses planned discussion in a non-threatening environment and makes use of the interactions between participants to obtain detailed information (Morgan, 1997). The Medical Ethics Committee of xx [blinded for review] gave a "declaration of no objection" for this study (MEC-2009-232).

Adolescent girls were recruited via migrant organizations and youth centres in a multicultural urban area (Rotterdam, the Netherlands) through convenience sampling. Recruitment via mental health services was avoided as the focus was on adolescent girls from the general population. Study information was sent to representatives of the entities who then invited the participants via telephone or email. Information letters were sent to the participants and their parents once they had shown initial interest. Participants were eligible to participate if their parents did not object to their participation, if they were female, aged between 12 and 20 years and with one of the following ethnic backgrounds: Dutch, Turkish or Moroccan. Turks and Moroccans made up respectively $7.8 \%$ and $6.5 \%$ of the population in Rotterdam, the Netherlands in 2011 (RotterdamDATA, 2012). After the Surinamese, the Turks and Moroccans are the largest migrant groups in Rotterdam. Most Turks and Moroccans immigrated to the Netherlands in the 1960's as guest workers. More recently, immigration took place mostly due to marital reasons. According to the latest statistics which date from 2010, Turkish and Moroccan immigrants in the Netherlands were on average lower educated and had a lower net family income than the majority population (CBS, 2010b, CBS, 2010a).

The focus group discussions (FGDs) took place in youth centres, centres for women, or mosques and were facilitated by one of two trained female researchers (IF and TB, both health psychologists) of Dutch ethnicity. A third researcher was present to take field notes. 
As all participants spoke Dutch, the FGDs were held in Dutch. Attention was paid to saturation of data. When no new themes arose data collection was ceased.

\section{Ethnic background}

Ethnic background was determined on the basis of the country of birth of the participant and her parents, a classification system employed by Statistics Netherlands (CBS, 2000). If the participant's parents were both born in the Netherlands, she was considered Dutch. If one of the participants' parents was born outside the Netherlands, she was considered non-Dutch. We further distinguished between first and second generation immigrants. Participants were considered first generation if they were born abroad. Participants were considered second generation if they were born in the Netherlands but if their mother or father was born abroad. Using country of birth as an indicator of ethnic background fits with the concept of a common geographical and ancestral origin in the conceptualization of ethnicity (Aspinall, 2001).

\section{Study instruments}

Vignette

According to Barter and Renold (Barter and Renold, 1999) "vignettes are useful in social research for three main purposes: (1) to allow actions in context to be explored; (2) to clarify people's judgments; and (3) to provide a less personal and therefore less threatening way of exploring sensitive topics". As mental health problems are seen as a sensitive topic in the Netherlands and elsewhere and the participants were selected from the general population, a vignette (presenting 'an internalizing problem') was employed to create a clear context and safe atmosphere in which to discuss the topic (Appendix 1). The vignette used for this study was based on real life stories and was reviewed by a child psychiatrist. 


\section{Focus group guide}

The FGDs were structured by means of a guide/list of questions (Appendix 2). The guide comprised three sections, each corresponding to the three stages of help-seeking. The guide had both general and probing questions framed on the three stages of help-seeking, the concepts of perceived severity, barriers and facilitating factors and, the vignette. Two additional prompts explored the influence of religion and ethnic background.

\section{Questionnaire}

In order to gain an idea of the characteristics of the participants and the FGDs, participants were invited to complete a questionnaire after the FGDs had ended. This questionnaire included items on background characteristics (i.e. education, religion, living situation), and the use of health services in the past year (i.e. general practitioner, mental health services, hospital).To take psychosocial well-being into account, the Strengths and Difficulties Questionnaire (SDQ) was also included (van Widenfelt et al., 2003). The SDQ is a brief behavioural screening instrument that asks about children's and teenagers' symptoms and positive attributes (Goodman, 1997, Goodman et al., 1998, Goodman, 2001). For this study the Total Difficulties scale was of interest. A cut-off value of 16 was used for this scale with a score above 16 indicating signs of emotional and social distress (Goodman, 1997, Goodman, 2001). The results of the questionnaire per FGD are presented in table 1.

\section{Content analysis}

Recordings from the FGDs were transcribed verbatim and entered into the NVivo (version 8) software program by the primary researcher (IF). A directed approach to content analysis was used to analyse the data. The goal of a directed approach is to "validate or extend conceptually a theoretical framework or theory" (Hsieh and Shannon, 2005). 
Firstly, a coding scheme using predetermined 'major themes' that were based on the three stages of mental health help-seeking (i.e. problem recognition, decision to seek help and service selection) and the Health Belief Model (i.e. perceived severity, barriers and facilitating factors) was developed by the first coder (IF) (Potter and Levine-Donnerstein, 1999, Hsieh and Shannon, 2005). All text that represented a 'major theme' was coded as such by the first coder (IF). Text that was deemed relevant for the study aim but that could not be highlighted with the coding scheme was given a new code.

In a next step, the coded text was analyzed extensively by two coders (IF \& TB). Firstly, all coded text was reviewed to determine whether it adequately represented the 'major theme'. This resulted in some minor changes (e.g. one passage was moved to another 'major theme'). Hereafter, the coders went on to identify 'subthemes' of the major themes. Data that were given a new code in the first step were re-analyzed to determine if the data represented a new 'major theme' or a 'subtheme'. This resulted in the addition of two new 'major themes' (i.e. consequences of not seeking help and causal attribution).

In a last step, a more quantitative approach in which frequency of categories (how many times a subtheme was mentioned) and extensiveness (how many participants mentioned the subtheme) was applied to identify the most important subthemes and potential differences between FGDs (Morgan et al., 1998, Pope and Mays, 2000). As a rule, it was decided that subthemes should be discussed in a majority of the FGDs by a majority of the participants to be considered an 'overall' finding (table 2). As a result of this analysis framework, five 'overall' subthemes were excluded. The coders additionally agreed that if a subtheme arose exclusively in a Turkish, Moroccan or Dutch FGD, it was considered as specific for that ethnic group (table 2).

In total, 7 major themes were identified with 21 corresponding subthemes (table 2). Both coders were involved in selecting appropriate passages of themes that could thereafter 
be translated into English by a bilingual researcher (IF). Each FGD and participant was numbered so that each selected passage could be labelled with this information.

\section{Results}

\section{Characteristics of the participants and the Focus Group Discussions}

A total of 50 girls participated in the eight FGDs, which were organized according to the participants' ethnic background (table 1). Three FGDs were classified as 'Turkish' (FGD 1, N=8; FGD 2, N=8; FGD 3, N=8), two as 'Moroccan' (FGD 4, N=8; FGD 5, N=5) and three as 'Dutch' (FGD 6, N=3; FGD 7, N=6; FGD 8, N=4). Four participants had an ethnic background other than Turkish, Moroccan or Dutch (i.e. Colombian, Bosnian and Surinamese). In view of small numbers, these participants were excluded from the content analysis. All participants provided their informed consent.

Most of the participants in the Turkish and Moroccan FGDs were second generation immigrants and felt most affiliated to the Muslim faith (table 1). In the Dutch FGDs most participants reported to have no religion. Median age of the FGD participants ranged from 13 (IQR 2) in FGD 6 (Dutch) to 21 (IQR 2) in FGD 1 (Turkish). In the Turkish FGDs, median age of the participants was slightly higher than in the other FGDs. In a majority of the FGDs, participants had a medium level education with the exception of one Turkish and one Dutch FGD where half of the participants had a high level education. In all FGDs most of the participants reported to live with both their parents. At least one participant in all FGDs had visited a General Practitioner (GP) the past year. A small minority had used other health services. In all FGDs the median score of the SDQ total difficulties scale was below the cutoff for psychological distress. Six participants presented a score above the cut-off. 
Table 1 Characteristics of the participants and the Focus Group Discussions (FGDs)

\begin{tabular}{|c|c|c|c|c|c|c|c|c|}
\hline & FGD 1 & FGD 2 & FGD 3 & FGD 4 & FGD 5 & FGD 6 & FGD 7 & FGD 8 \\
\hline & 'Turkish' & 'Turkish’ & 'Turkish' & 'Moroccan' & 'Moroccan' & 'Dutch' & 'Dutch' & 'Dutch' \\
\hline & $(\mathrm{N}=8)$ & $(\mathrm{N}=8)^{1}$ & $(\mathrm{~N}=8)$ & $(\mathrm{N}=8)$ & $(\mathrm{N}=5)^{2}$ & $(\mathrm{~N}=3)$ & $(\mathrm{N}=6)^{3}$ & $(\mathrm{~N}=4)^{4}$ \\
\hline \multicolumn{9}{|l|}{ Generational status } \\
\hline$\%(\mathrm{~N})$ Second generation & $100(8)$ & $88(6)$ & $100(8)$ & $75(6)$ & $100(4)$ & $0(0)$ & $0(0)$ & $25(1)$ \\
\hline \multicolumn{9}{|l|}{ Age (years) } \\
\hline Median (IQR) & $21(2)$ & $17(4)$ & $19(5)$ & $16(2)$ & $16(2)$ & $13(2)$ & $14(2)$ & $15(2)$ \\
\hline \multicolumn{9}{|l|}{ Educational level $\%(\mathrm{~N})$} \\
\hline High & $25(2)$ & $12(1)$ & $50(4)$ & $38(3)$ & $0(0)$ & $0(0)$ & $17(1)$ & $50(2)$ \\
\hline Medium & $75(6)$ & $88(7)$ & $38(3)$ & $50(4)$ & $100(4)$ & $100(3)$ & $83(5)$ & $50(2)$ \\
\hline Low & $0(0)$ & $0(0)$ & $12(1)$ & $12(1)$ & $0(0)$ & $0(0)$ & $0(0)$ & $0(0)$ \\
\hline \multicolumn{9}{|l|}{ Religious affiliation $\%(\mathrm{~N})$} \\
\hline Muslim & $100(8)$ & $100(7)$ & $100(8)$ & $100(8)$ & $100(5)$ & N.A. ${ }^{5}$ & $0(0)$ & $25(1)$ \\
\hline Christian & $0(0)$ & $0(0)$ & $0(0)$ & $0(0)$ & $0(0)$ & N.A. ${ }^{5}$ & $33(2)$ & $25(1)$ \\
\hline Other religion & $0(0)$ & $0(0)$ & $0(0)$ & $0(0)$ & $0(0)$ & N.A. ${ }^{5}$ & $17(1)$ & $0(0)$ \\
\hline No religion & $0(0)$ & $0(0)$ & $0(0)$ & $0(0)$ & $0(0)$ & N.A. ${ }^{5}$ & $50(2)$ & $50(2)$ \\
\hline
\end{tabular}




\begin{tabular}{|c|c|c|c|c|c|c|c|c|}
\hline \multicolumn{9}{|l|}{ Living situation } \\
\hline$\%(\mathrm{~N})$ Living with both parents & $100(7)$ & $75(6)$ & $88(7)$ & $63(5)$ & $60(3)$ & N.A. ${ }^{5}$ & $67(4)$ & $75(3)$ \\
\hline \multicolumn{9}{|l|}{ Health service use past year $(\mathrm{N})$} \\
\hline General practitioner & 3 & 4 & 8 & 5 & 2 & N.A. ${ }^{5}$ & 3 & 3 \\
\hline Mental health care & 1 & 0 & 0 & 0 & 0 & N.A. ${ }^{5}$ & 0 & 1 \\
\hline Medical specialist & 2 & 0 & 0 & 0 & 0 & N.A. ${ }^{5}$ & 1 & 0 \\
\hline Social worker & 1 & 0 & 0 & 0 & 1 & N.A. ${ }^{5}$ & 0 & 1 \\
\hline Peer help & 0 & 0 & 0 & 0 & 0 & N.A. ${ }^{5}$ & 0 & 1 \\
\hline Youth health care & 0 & 0 & 0 & 0 & 0 & N.A. ${ }^{5}$ & 0 & 1 \\
\hline \multicolumn{9}{|l|}{ SDQ total difficulties score ${ }^{6}$} \\
\hline Median (IQR) & $14(6)$ & $9(4)$ & $12(6)$ & $6(5)$ & $13(4)$ & $14(13)$ & $13(6)$ & $13(5)$ \\
\hline SDQ total difficulties score $>16 \%(\mathrm{~N})$ & $25(2)$ & $0(0)$ & $0(0)$ & $0(0)$ & $0(0)$ & $33(1)$ & $33(2)$ & $25(1)$ \\
\hline \multicolumn{9}{|c|}{$\begin{array}{l}{ }^{1} \text { FGD included one participant of Colombian background } \\
{ }^{2} \text { FGD included one participant of Bosnian background } \\
3 \text { FGD included one participant of Surinamese background } \\
{ }^{4} \text { FGD included one participant of Surinamese and one participant of Moroccan background } \\
{ }^{5} \text { Data not available } \\
{ }^{6} \text { Normal range 0-16 for girls. Score }>16 \text { indicates some form of distress (Goodman, 2001) }\end{array}$} \\
\hline
\end{tabular}


Phase I Problem recognition: perceived severity and consequences of not seeking help

11 Participants of the FGDs recognized that the character described in the vignette had a problem. Suicide or contact with 'lover boys' (pimps) were mentioned as a possible consequence of not seeking help: "If she keeps on crying then at some point she'll probably think she doesn't want to live anymore. I think you'll get those kinds of thoughts quite quickly" (Turkish FGD 2, participant 1), "I think things are only going to get worse if she doesn't talk to anyone. It may even lead to suicide or she might get in touch with a lover boy" (Dutch FGD 8, participant 4). Despite stating these consequences, participants of the FGDs did not perceive the problem in the vignette as severe. They indicated that it was a normal problem that every teenager has to deal with "But it could be any random girl. She's just going through puberty. I think any girl who's 15 feels like this" (Moroccan FGD 4, participant 5).

\section{Ethnic background, problem recognition and causal attribution}

A marked difference between Dutch and non-Dutch FGDs was the way participants described the problem. When asked what was 'wrong' with the character in the vignette, participants of Dutch FGDs more often identified the emotional state (i.e. depression) whereas the participants of Turkish and Moroccan FGDs more often named the cause. Facilitator: "So what do you think is wrong with this girl?" "I think that she's just depressed about everything” (Dutch FGD 7, participant 5) "I think she's getting too little attention” (Moroccan 30 FGD 4, participant 10).

Phase II Decision to seek help: perceived barriers and facilitating factors

In all FGDs, distrust was identified as an important barrier to seeking help. In particular, 
school-based services (i.e. teachers) were identified as untrustworthy by participants: "Some teachers immediately tell others" "But of course you do have counsellors or doctors; they also come to the schools." "Either way, you need to know how a teacher will react otherwise you'll never tell them" (Turkish FGD 2, multiple participants). “They're always going to tell your parents. They'll tell you that they won't - but they'll phone them anyway" (Dutch FGD 7, participant 5).

In Turkish and Dutch FGDs, participants who had been in contact with formal mental health services had negative attitudes towards these services based on previous experiences. Participants indicated that professionals often "talk things into your head" which makes the problem even worse: "Well at some point I even got into a fight with the professional at the institution, I wasn't allowed to come back. They'd ask me the same question 100 times. At some point I said: if "yes" is what you want to hear then I'll say YES!" (Dutch FGD 8, participant 4).

Even the participants without direct experience had negative attitudes: "Well I haven't been there myself, but a friend of mine went and she said that all those stories - that your problems only get worse and that you need to talk about your problems all the time - are true. At least that's what I understood. It must be a method or something” (Turkish FGD 1, participant 7).

Participants of the FGDs felt that having more self-confidence would facilitate help seeking, but would also be a solution to the problem: "If you're self-confident then things will just be better" (Turkish FGD 2, participant 1).

\section{Ethnic background, perceived barriers and facilitating factors}

The fear of negative reactions of family/friends represented a barrier for participants of the FGDs. However, in Turkish and Moroccan FGDs the fear of negative reactions was identified 
as a barrier more often than in Dutch FGDs. Additionally, different types of negative reactions were identified compared to Dutch FGDs; most participants of non-Dutch FGDs particularly feared disappointing, worrying or shaming their parents: "Well I think shame plays a role - but also being scared that they're going to be too worried about you. You want to show your parents that things are going well with you - and that you're doing well at school for instance" (Moroccan FGD 4, participant 1). Participants also feared the reactions of friends "There might be friends that will think that you're crazy or something" (Turkish FGD 1, participant 1). Participants of Dutch FGDs preferred not to tell their parents because they thought they would not take them seriously: “I don't even dare tell anything. I know that my mom won't react negatively but I'm just scared that she won't understand me" (Dutch FGD 8, participant 4).

In Dutch FGDs, participants agreed that they would not go to a professional because they are not familiar/known to you: "Well you're not familiar with those people. You're not really sure if the things you tell them will be interpreted in the right way" (Dutch FGD 6, participant 2).

Opinions about whether a professional should have the same ethnic background were not unanimous. Participants of Turkish and Moroccan FGDs indicated that a professional with the same cultural background would be able to help them better: "I don't understand how someone with a different cultural background can understand me if I have problems at home that they don't experience" (Turkish FGD 1, participant 1). However, others indicated that it did not matter to them, or that they would even prefer to visit a Dutch professional: Facilitator: "Would it help if the psychiatrist was Moroccan?" "I would be ashamed, maybe it's family. That's often the case in the Moroccan community" (Moroccan FGD 4, participant 1). Participants of Turkish FGDs in particular mentioned that seeking help from a Dutch professional would make help-seeking easier because the conversation is confidential and 
because you do not know them personally: "I would convince her to seek help from a psychologist that she doesn't know. That's always easier" (Turkish FGD 3, participant 1).

\section{Phase III Service selection}

When asked whom they would talk to about their problems first, participants of the FGDs said this would either be a close friend or their mother. The reason for choosing their mother was because she is trustworthy and knows you very well: "Moms can just feel everything. I, for instance, can't lie to my mom. I find it so weird - but she always knows the truth!” (Moroccan FGD 4, participant 1). Friends were identified as the first person to talk to because you see them regularly: "I think my friends will be the first to notice that things aren't going well with me ... so because of that I'd speak to my friends about it first" (Dutch FGD 7, participant 1).

Although participants preferred not to go to a teacher for help related to internalizing problems, school counsellors and teachers were nonetheless identified as helpful when it came to issues related to school: "Well it depends, look - if I'm not feeling well but at school everything is going all right I won't tell a teacher. But if things aren't going well at school either, then I'd tell them rather than keep quiet”' (Moroccan FGD 5, participant 6). Participants of the FGDs indicated that seeking help from a formal mental health service was only necessary if you have a very serious problem. They considered that the problems of the character in the vignette were not severe enough: "If you have very serious problems - not like this girl because her problems aren't that serious - well then I'd seek some professional help" (Turkish FGD 2, participant 4). 


\begin{tabular}{|c|c|c|c|c|}
\hline \multirow[t]{2}{*}{ Major themes } & \multicolumn{4}{|c|}{ Subthemes } \\
\hline & $\begin{array}{c}\text { All FGDs } \\
\text { (overall findings) }\end{array}$ & Turkish FGDs & Moroccan FGDs & Dutch FGDs \\
\hline $\begin{array}{l}\text { Problem recognition \& } \\
\text { causal attribution }\end{array}$ & & $\begin{array}{c}\text { Puberty } \\
\text { Lack of attention }\end{array}$ & $\begin{array}{c}\text { Puberty } \\
\text { Insecurity }\end{array}$ & $\begin{array}{l}\text { "Depressed" or } \\
\text { "psychological" } \\
\text { problem }\end{array}$ \\
\hline Perceived severity & $\begin{array}{l}\text { Normal for } \\
\text { teenage girls }\end{array}$ & & & \\
\hline $\begin{array}{l}\text { Perceived consequences of } \\
\text { not seeking help }\end{array}$ & $\begin{array}{c}\text { Suicide } \\
\text { loverboys (pimps) }\end{array}$ & & & \\
\hline $\begin{array}{l}\text { Perceived barriers of help- } \\
\text { seeking }\end{array}$ & $\begin{array}{c}\text { Distrust } \\
\text { professional help } \\
\text { at school } \\
\text { Negative } \\
\text { experience with } \\
\text { mental health } \\
\text { care } \\
\text { Negative attitudes } \\
\text { towards mental } \\
\text { health care }\end{array}$ & $\begin{array}{l}\text { Fear of parental } \\
\text { shame }\end{array}$ & $\begin{array}{l}\text { Fear of parental } \\
\text { shame }\end{array}$ & $\begin{array}{c}\text { Shame of } \\
\text { disclosing to } \\
\text { strangers } \\
\text { (professionals) } \\
\text { Fear of not being } \\
\text { taken seriously or } \\
\text { believed }\end{array}$ \\
\hline Facilitating factors & Self-security & $\begin{array}{l}\text { Anonymity } \\
\text { (Dutch } \\
\text { professional) }\end{array}$ & $\begin{array}{l}\text { Anonymity } \\
\text { (Dutch } \\
\text { professional) }\end{array}$ & \\
\hline & & $\begin{array}{l}\text { Cultural } \\
\text { understanding } \\
\text { (Turkish } \\
\text { professional) }\end{array}$ & $\begin{array}{l}\text { Cultural } \\
\text { understanding } \\
\text { (Moroccan } \\
\text { professional) }\end{array}$ & \\
\hline
\end{tabular}

Service selection

Mothers

Friends

School (schoolrelated problems)

$$
\begin{aligned}
& \text { Formal help } \\
& \text { through mental } \\
& \text { health } \\
& \text { professional (last } \\
& \text { option) }
\end{aligned}
$$


112 This study showed that, although adolescent girls could clearly envision the long-term

113 consequences of internalizing problems, the problems presented in the vignette were not

114 identified as severe. Participants indicated that if they were to face an internalizing problem of 115 their own, negative attitudes towards professionals and school-based services, as well as fear 116 of certain reactions from parents and friends, might hamper them from seeking help. Despite 117 these feared reactions, participants indicated they would first seek help from friends or their 118 mothers when dealing with internalizing problems. recognition of the problem described in the vignette. Participants of Turkish and Moroccan

121 FGDs more often referred to the cause of the problem (e.g. lack of attention) while

122 participants of Dutch FGDs referred to the emotional state (e.g. depression). Other studies

123 have also shown that causal attributions may differ according to ethnic background (Cho et al,

124 2008; Karasz, 2007). In turn, it has been found that causal attributions influence help-seeking

125 pathways, communication with clinicians, treatment compliance and the course of illness

126 (Kirmayer et al., 1994). In a Turkish study, Gulek (Gulec, 2008) found that normalizing

127 attribution (when a person looks for an external or environmental explanation of disease)

128 negatively influences help-seeking behaviour for fibromyalgia and contributes to non-help-

129 seeking. Han et al. (Han et al., 2006) found that attribution to an internal cause of a problem

130 (i.e. insecurity) hampers help-seeking whereas holding a more biological conceptualizing of a 131 disease enhances help-seeking. The differences in causal attributions found in this study may

132 be a possible explanation for the underutilization of mental health services in ethnic minority 133 youth.

134 We further found that the adolescent girls in this study had difficulty recognizing the 135 severity of the internalizing problems presented in the vignette. This is in line with a study on 
suicidality and help-seeking in African American adolescents (Molock et al., 2007). A probable explanation for this finding might be that internalizing problems are more often overlooked, since they are less disruptive than externalizing problems (Leighton, 2010). In addition, adolescence might be a phase of life that makes it more difficult to distinguish between puberty-related issues and serious ongoing problems.

This study revealed that, should an internalizing problem arise, negative attitudes towards mental health professionals and school-based care would form a barrier to the decision to seek help. Other studies on ethnic minority groups and adolescents reported similar findings (Barker, 1994, Garland and Zigler, 1994). We found that these attitudes are often caused by a negative experience, e.g. a teacher contacts the parents and the problem subsequently gets known by others. This also explains why our participants preferred to seek help from a friend or their mother rather than from a professional or school social worker. This study further revealed that participants of Turkish FGD's perceived seeking help from a professional, some one that is unknown to you, as a facilitating factor, whereas participants of Dutch FGDs perceived this to be a barrier. This may be because particularly in this study adolescents from ethnic minority groups feared 'shame and gossiping' and would therefore prefer to seek help from an anonymous/confidential source.

$$
\text { Another difference between the Dutch and non-Dutch FGDs was that participants of }
$$
Moroccan and Turkish FGDs more often feared negative reactions of parents and friends than participants of Dutch FGDs, and also indicated that the reactions of parents/friends would hamper disclosure. Studies among Asian migrants in the USA and the UK reported similar results (Lawrence et al., 2006, Lee et al., 2009). One reason for this may be the differences in family roles, parenting style and stigmatization of mental health problems, which are often influenced by cultural norms (Varela et al., 2004, Lawrence et al., 2006). Though this research did not indicate a specific role of religious norms, these factors may have also 
contributed to the differences in perceptions, particularly given that participants from the ethnic minority groups were mostly Muslim.

In the present study adolescent girls preferred to firstly turn to their friends or mothers

164 when dealing with an internalizing problem, as also reported by others (Offer et al., 1991,

165 Boldero, 1995, Frojd et al., 2007, Rickwood et al., 2007). We found no differences between

166 the Dutch and non-Dutch FGDs regarding whom adolescent girls would turn to. It is

167 noteworthy that the fear of negative reactions from mothers and/or friends would not stop the 168 participants in this study from seeking help from them. As found in this study and others

169 (Rickwood et al., 2007) this is probably because once they have overcome the barriers,

170 mothers and friends are the most trustworthy and accessible persons to turn to. Additionally,

171 this may also be related to the fact that they are adolescents (i.e. neither children nor adults)

172 and thus fall in between various social systems (Cauce et al., 2002).

173 Some methodological issues need to be addressed. A positive aspect of this study is

174 that it included adolescent girls from ethnic minorities and the majority group hence

175 facilitating the cross-cultural comparison of perceptions regarding mental health help-seeking.

176 This study also had several limitations. Firstly, the facilitators were of Dutch origin, which

177 might imply that they had more difficulty interpreting the discussions and asking appropriate

178 questions in the Moroccan and Turkish FGDs. To reduce this influence, prompts on cultural

179 and religious factors (e.g. whether the participants would turn to a religious clergy) were

180 available for Moroccan and Turkish FGDs. These however proved unnecessary as the

181 participants openly discussed these topics without the prompts. To make the FGDs as

182 comparable as possible, a focus group guide was applied. This created a clear context but the

183 use of these tools might also have restricted the discussion. In addition, the text used to

184 illustrate the results of this study was translated from Dutch to English by a bilingual

185 researcher; some information may have been lost during the translation process. Also, two of 
the groups had less than five respondents; the results from these groups were only used when they were confirmed in other larger groups. Four participants had an ethnic background other than Dutch, Turkish or Moroccan. Although we excluded these participants from the content analysis it should be noted that these girls nevertheless participated in three focus group discussions and they may have had a minor influence on the discussions. The participants in this study were recruited through convenience sampling hence making it difficult to generalize this study's findings to the larger population of adolescent girls in Rotterdam with Dutch, Moroccan and Turkish backgrounds. For instance, the great majority of the ethnic minority participants included in this study were second-generation immigrants and results can therefore not be generalized to $1^{\text {st }}$ generation immigrants, who are

196 likely to vary in their levels of acculturation and help-seeking behaviour (Knipscheer and

197 Kleber, 2005, Cabassa and Zayas, 2007). Furthermore, the presence of internalizing problems was not an inclusion criterion for participation. Findings may therefore not be representative to adolescents with internalizing problems. It should also be noted that the FGDs varied according to age and educational level. Consequently, we cannot rule out that these characteristics may have partly influenced the participant's perceptions. better known to teenage girls (e.g. via awareness-raising campaigns in schools and communities) and facilitating help-seeking from friends or mothers. School resources like peer discussion groups or parent-teacher meetings may be helpful in this regard. Besides this,

206 little is known about the roles and perceptions of peers and mothers in the help-seeking 207 process. More research insights into this issue are recommended. Considering the negative attitudes of the adolescent girls towards mental health services and school-based services 209 found in this study, it may be beneficial to more closely match the available services to the needs of adolescent girls from diverse ethnic backgrounds. This study also showed that 
211 guaranteeing confidentiality in the school setting, and specific training for professionals in

212 working with adolescent girls and their problems, may be important.

213

\section{Key messages}

215 This study explored how adolescent girls with different ethnic backgrounds perceive help-

216 seeking behaviour for internalizing problems. We found that participants of mostly Turkish,

217 Moroccan and Dutch backgrounds had difficulty assessing the severity of internalizing

218 problems and, should a problem arise, they would be hampered by negative attitudes towards

219 school-based services and mental health professionals. Mothers and friends were identified as

220 primary sources of help by all participants. In non-Dutch FGDs, participants were found to

221 describe the internalizing problems presented in the vignette differently than participants of

222 Dutch FGDs and the fear of reactions of their parents and friends was more often identified as 223 a barrier than by participants of Dutch FGDs. 


\section{References}

Achenbach, T. \& Rescorla, L., 2000. Manual for the ASEBA Preschool Forms \& Profiles Burlington, VT: University of Vermont, Research Center for Children, Youth \& Families.

Aspinall, P., 2001. Operationalising the collection of ethnicity data in studies of the sociology of health and illness. Sociology of Health and Illness, 23, 829-862.

Barker, L.A., Hs, 1994. Mental Health and Help-seeking among Ethnic Minority Adolescents. Journal of Adolescence, 17, 251-263.

Barter, C. \& Renold, E., 1999. The Use of Vignettes in Qualitative Research Social Research Update.

Boldero, J.F., B., 1995. Adolescent help-seeking: what do they get help for and from whom? Journal of Adolescence, 18, 193-209.

Cabassa, L.J. \& Zayas, L.H., 2007. Latino immigrants' intentions to seek depression care. Am J Orthopsychiatry, 77, 231-42.

Carlson, G.A., 2000. The challenge of diagnosing depression in childhood and adolescence. Journal of Affective Disorders, 61, S4-S8.

Cauce, A.M., Domenech-Rodriguez, M., Paradise, M., Cochran, B.N., Shea, J.M., Srebnik, D. \& Baydar, N., 2002. Cultural and contextual influences in mental health help seeking: a focus on ethnic minority youth. J Consult Clin Psychol, 70, 44-55.

Cbs, 2000. Standaard definitie allochtonen (standard definition migrant) Index.

Cbs, 2010a. Average household income according to ethnic background. The Hague/Heerlen: Centraal Bureau voor de Statistiek.

Cbs, 2010b. Higher educated according to ethnic background. The Hague/Heerlen: Centraal Bureau voor de Statistiek.

De Haan, A.M., Boon, A.E., Vermeiren, R.R. \& De Jong, J.T., 2012. Ethnic differences in utilization of youth mental health care. Ethn Health, 17, 105-10.

Frojd, S., Marttunen, M., Pelkonen, M., Von Der Pahlen, B. \& Kaltiala-Heino, R., 2007. Adult and peer involvement in help-seeking for depression in adolescent population: a two-year follow-up in Finland. Soc Psychiatry Psychiatr Epidemiol, 42, 945-52.

Garland, A.F., Lau, A.S., Yeh, M., Mccabe, K.M., Hough, R.L. \& Landsverk, J.A., 2005. Racial and ethnic differences in utilization of mental health services among high-risk youths. Am J Psychiatry, 162, 1336-43.

Garland, A.F. \& Zigler, E.F., 1994. Psychological correlates of help-seeking attitudes among children and adolescents. Am J Orthopsychiatry, 64, 586-93.

Goldston, D.B., Molock, S.D., Whitbeck, L.B., Murakami, J.L., Zayas, L.H. \& Hall, G.C., 2008. Cultural considerations in adolescent suicide prevention and psychosocial treatment. Am Psychol, 63, 14-31.

Goodman, R., 1997. The Strengths and Difficulties Questionnaire: a research note. J Child Psychol Psychiatry, 38, 581-6.

Goodman, R., 2001. Psychometric properties of the strengths and difficulties questionnaire. $J$ Am Acad Child Adolesc Psychiatry, 40, 1337-45.

Goodman, R., Meltzer, H. \& Bailey, V., 1998. The Strengths and Difficulties Questionnaire: a pilot study on the validity of the self-report version. Eur Child Adolesc Psychiatry, 7, 125-30.

Gulec, H., 2008. Normalizing attributions may contribute to non-help-seeking behavior in people with fibromyalgia syndrome. Psychosomatics, 49, 212-7.

Han, D.Y., Chen, S.H., Hwang, K.K. \& Wei, H.L., 2006. Effects of psychoeducation for depression on help-seeking willingness: biological attribution versus destigmatization. 
Psychiatry Clin Neurosci, 60, 662-8.

Harrington, R., Fudge, H., Rutter, M., Pickles, A. \& Hill, J., 1990. Adult Outcomes of Childhood and Adolescent Depression .1. Psychiatric Status. Archives of General Psychiatry, 47, 465-473.

Hsieh, H.F. \& Shannon, S.E., 2005. Three approaches to qualitative content analysis. Qual Health Res, 15, 1277-88.

Jorm, A.F., 1987. Sex and age differences in depression: a quantitative synthesis of published research. Aust N Z J Psychiatry, 21, 46-53.

Kirmayer, L.J., Young, A. \& Robbins, J.M., 1994. Symptom attribution in cultural perspective. Can J Psychiatry, 39, 584-95.

Knipscheer, J.W. \& Kleber, R.J., 2005. Help-seeking behaviour regarding mental health problems of Mediterranean migrants in the Netherlands: familiarity with care, consultation attitude and use of services. Int J Soc Psychiatry, 51, 372-82.

Kuehner, C., 2003. Gender differences in unipolar depression: an update of epidemiological findings and possible explanations. Acta Psychiatr Scand, 108, 163-74.

Lawrence, V., Banerjee, S., Bhugra, D., Sangha, K., Turner, S. \& Murray, J., 2006. Coping with depression in later life: a qualitative study of help-seeking in three ethnic groups. Psychol Med, 36, 1375-83.

Lee, S., Juon, H.S., Martinez, G., Hsu, C.E., Robinson, E.S., Bawa, J. \& Ma, G.X., 2009. Model minority at risk: expressed needs of mental health by Asian American young adults. J Community Health, 34, 144-52.

Leighton, S., 2010. Using a vignette-based questionnaire to explore adolescents' understanding of mental health issues. Clin Child Psychol Psychiatry, 15, 231-50.

Mclaughlin, K.A., Hilt, L.M. \& Nolen-Hoeksema, S., 2007. Racial/ethnic differences in internalizing and externalizing symptoms in adolescents. J Abnorm Child Psychol, 35, 801-16.

Molock, S.D., Barksdale, C., Matlin, S., Puri, R., Cammack, N. \& Spann, M., 2007. Qualitative study of suicidality and help-seeking behaviors in African American adolescents. Am J Community Psychol, 40, 52-63.

Morgan, D., 1997. Focus groups as qualitative research, 2nd ed ed.: Thousand Oaks, CA: Sage Publications, Inc.

Morgan, D., Krueger, R. \& King, J., 1998. The focus group kit: Thousand Oaks, CA: Sage Publications, Inc.

Offer, D., Howard, K.I., Schonert, K.A. \& Ostrov, E., 1991. To whom do adolescents turn for help? Differences between disturbed and nondisturbed adolescents. J Am Acad Child Adolesc Psychiatry, 30, 623-30.

Pope, C. \& Mays, N., 2000. Qualitative Research in Health Care, Second ed. London: BMJ Books.

Potter, W.J. \& Levine-Donnerstein, D., 1999. Rethinking validity and reliability in content analysis. Journal of Applied Communication Research, 27, 258-284.

Rickwood, D.J., Deane, F.P. \& Wilson, C.J., 2007. When and how do young people seek professional help for mental health problems? Med J Aust, 187, S35-9.

Rosenstock, I.M., Strecher, V.J. \& Becker, M.H., 1988. Social-Learning Theory and the Health Belief Model. Health Education Quarterly, 15, 175-183.

Rotterdamdata, 2012. [Population 2005-2011, Number of people 2005-2011, according to different characteristics] Bevolking 2005-2011, Aantal personen 2005-2011, naar diverse kenmerken. 2011 ed. Rotterdam: Publiekszaken Rotterdam, Bewerking COS.

Sampson, E., 1988. The debate on individualism: Indigenous psychologies of the individual and their role in personal and societal functioning. American Psychologist, 43, 15-22.

Shaffer, D., Gould, M.S., Fisher, P., Trautman, P., Moreau, D., Kleinman, M. \& Flory, M., 
1996. Psychiatric diagnosis in child and adolescent suicide. Archives of General Psychiatry, 53, 339-348.

Simon, N.M., 2009. Generalized Anxiety Disorder and Psychiatric Comorbidities Such as Depression, Bipolar Disorder, and Substance Abuse. Journal of Clinical Psychiatry, 70, 10-14.

Stevens, G.W., Vollebergh, W.A., Pels, T.V. \& Crijnen, A.A., 2005. Predicting internalizing problems in Moroccan immigrant adolescents in The Netherlands. Soc Psychiatry Psychiatr Epidemiol, 40, 1003-11.

Van Oort, F.V., Joung, I.M., Van Der Ende, J., Mackenbach, J.P., Verhulst, F.C. \& Crijnen, A.A., 2006. Internalising and externalising behaviours in young adults: Dutch natives and Turkish migrants in the Netherlands. Ethn Health, 11, 133-51.

Van Widenfelt, B.M., Goedhart, A.W., Treffers, P.D. \& Goodman, R., 2003. Dutch version of the Strengths and Difficulties Questionnaire (SDQ). Eur Child Adolesc Psychiatry, 12, 281-9.

Varela, R.E., Vernberg, E.M., Sanchez-Sosa, J.J., Riveros, A., Mitchell, M. \& Mashunkashey, J., 2004. Parenting style of Mexican, Mexican American, and Caucasian-non-Hispanic families: social context and cultural influences. J Fam Psychol, 18, 651-7. 


\section{Acknowledgements}

346 We thank the girls that were willing to participate in this study and share their views with us.

347 We also thank the youth centres and migrant organisations for helping us with recruiting the

348 participants and informing them. Additionally, our appreciation goes out to the co-moderators

349 that assisted us during the focus group discussions. This study was funded by a grant from

350 ZonMW (grant number 15501000), the Netherlands organisation for health research and

351 development, as part of their program on Diversity in Youth Policy.

352 
Dina, aged 15 years

Dina is from a family with four children. For some time now things haven't been going well for her. She cries a lot and doesn't sleep well. For nights in a row she lies worrying: about school, about boys and about the situation at home. At school, her classmates bully her and laugh at her. She thinks it's because she always blushes during presentations. Also, her grades are not good: there's even a possibility she won't pass this year. Her parents don't agree with this and have spoken to her teacher several times. At home they're always moaning about her

364 low grades. Her brothers and sisters don't interfere with her life. Dina thinks they're better at 365 everything anyway.

For some time, she hasn't been in the mood for school. She has skipped some classes already, preferring to stay in bed all day, to listen to music and to ponder. 
1. What do you think is wrong with Dina?

2. Do you think it's serious/severe?

3. What could happen to Dina if she doesn't seek help?

4. Why do you think she has these problems?

5. (for Moroccan and Turkish groups only) Do you think that a Moroccan or Turkish girl could also have these kinds of problems?

6. How would your friends react if you had such a problem?

7. How would other people from your environment react (i.e. mother, father, teachers or other family members)?

8. How important do you find it is for Dina to seek help?

9. Imagine you're dealing with the same problems, who would you approach for help?

10. Which obstacles would hold you back from seeking help?

11. What would make seeking help easier?

12. Do you think Dina can seek help by herself?

13. Do you know anyone that has sought help for problems like these?

14. Can you tell us a little more about it?

15. Should Dina have sought help earlier?

16. When should she have done that?

17. Can Dina solve her problems by herself?

18. How can friends help?

19. How can parents help?

20. How can teachers help?

21. How can professionals (GPs, social workers, psychologists) help?

22. (for Moroccan and Turkish groups only) Say Dina is a Moroccan or Turkish girl, are there any members of the clergy or religious gatekeepers she can turn to?

23. Are some groups more vulnerable for these kinds of problems?

24. What do you think causes these problems? 